\title{
Association between multimorbidity and mean platelet volume in diabetic patients with acute myocardial infarction
}

\author{
Bartosz Hudzik ${ }^{1,2}$ (1) $\cdot$ Ilona Korzonek-Szlacheta ${ }^{2}$ Janusz Szkodziński ${ }^{1} \cdot$ Radosław Liszka $^{1}$. Andrzej Lekston ${ }^{1}$ \\ Barbara Zubelewicz-Szkodzińska ${ }^{2}$ Mariusz Gąsior ${ }^{1}$
}

Received: 5 October 2017 / Accepted: 8 November 2017 / Published online: 30 November 2017

(c) The Author(s) 2017. This article is an open access publication

\begin{abstract}
Aims Diabetes mellitus (DM) is one of the most frequently detected conditions in multimorbid disease clusters. Platelet activation is one of the key mechanisms underlying atherothrombosis in acute myocardial infarction. Available data link mean platelet volume (MPV) to poor prognosis not only in cardiovascular and non-cardiovascular disease. Given the lack of research data on the association between disease clusters and MPV, we have set out to investigate the link between multimorbidity and MPV in diabetic patients with acute myocardial infarction.

Methods A total of 277 patients with DM and STEMI undergoing primary percutaneous coronary intervention were enrolled. Based on the number of comorbidities the study population was divided into two groups: group $1(N=58)$ with $\leq 1$ comorbidity and group $2(N=219)$ with $\geq 2$ comorbidities. A subanalysis was performed within the multimorbidity group: group 2A with two or three comorbidities $(N=156)$ and group 2B with at least four comorbidities $(N=63)$.

Results In the study population, $15.9 \%$ of patients had one comorbidity, and 22.0, 34.3, and 22.7\% of patients had two, three, or at least four comorbid conditions, respectively. Both MPV and PDW were elevated in multimorbid patients (9.3 vs $10.8 \mathrm{fl}$ and $9.5 \mathrm{vs} 10.3 \mathrm{fl}$, respectively). The highest platelet volume indices were observed in patients with at least four comorbid conditions. There was a moderate positive correlation between MPV and the total number of comorbidities, the number of CVD comorbidities, and the number of non-CVD comorbidities.

Conclusions These findings indicate that multimorbidity is associated with an increase in platelet volume indices. MPV values increased with the increasing number of comorbid conditions. Importantly, MPV values were elevated in some, but not all CVD and non-CVD conditions.
\end{abstract}

Keywords Multimorbidity $\cdot$ Diabetes mellitus $\cdot$ Myocardial infarction $\cdot$ Mean platelet volume

Managed By Antonio Secchi.

Bartosz Hudzik and Ilona Korzonek-Szlacheta have contributed equally to this work.

Bartosz Hudzik

bartekh@mp.pl

1 Third Department of Cardiology, Silesian Center for Heart Disease, School of Medicine with the Division of Dentistry in Zabrze, Medical University of Silesia, Katowice, Poland

2 Department of Nutrition-Related Disease Prevention, School of Public Health in Bytom, Medical University of Silesia, Katowice, Poland

\section{Introduction}

Type 2 diabetes mellitus (DM) has become one of the more prevalent conditions worldwide in the past few decades [1]. $\mathrm{DM}$ is a chronic condition that is associated with a plethora of complications. This, in turn, results in high morbidity and mortality. Diabetic patients have at least one coexisting chronic disease and approximately $40 \%$ have at least three $[2,3] . \mathrm{DM}$ is one of the most commonly measured diseases in studies of multimorbidity, and more importantly it is one of the most frequently detected conditions in multimorbid disease clusters $[4,5]$. Patients with diabetes mellitus who are hospitalized for other health problems may have increased risk of in-hospital death and longer hospital stay. For this reason, diabetes should be promptly recognized upon admission and properly managed [6]. That said, 
the risk of cardiovascular and other macrovascular complications varies substantially among diabetic patients [7, 8]. Diabetes is a major contributor to the development of cardiovascular disease (CVD), stroke, chronic kidney disease, non-traumatic lower limb amputations, and blindness. Growing number of chronic diabetes-related complications and comorbid conditions have been associated with poor metabolic control, less optimal disease management, higher health service utilization, impaired physical functioning, and worse outcomes [5, 9-11].

Platelet activation is one of the key mechanisms underlying atherothrombosis in acute myocardial infarction [12]. Platelets of diabetic patients are characterized by dysregulation of several signaling pathways, which leads to increased platelet reactivity. This may play a role not only in the higher risk of developing acute myocardial infarction and the worse outcomes observed in DM, but also in the larger proportion of DM patients with inadequate response to antiplatelet agents compared with non-DM patients [13]. The methods of testing platelet activity may be very time consuming, expensive, and technically difficult [14]. The mean platelet volume (MPV) is a readily available parameter with routine blood counts by automated hemograms and, therefore, is an attractive index to study in clinical scenarios [15]. Available data show that increased MPV is linked to the presence of risk factors for cardiovascular disease including among others: diabetes mellitus [16], impaired fasting glucose [17], hyperlipidemia [18], and metabolic syndrome [19]. MPV is a marker of platelet size and activity and has been linked to poor prognosis following St elevation myocardial infarction (STEMI) [20, 21]. In this sense, regular glycemic control could result in lowering disease burden, especially when DM itself and glycemia have a great impact on platelet function [22-24].

Available data link MPV to poor prognosis not only in cardiovascular disease, but also in malignant tumors, chronic kidney disease, lung disease, kidney disease, and rheumatoid condition among others [25-28]. Given lack of research data on the association between disease clusters and MPV, we have set out to investigate the link between multimorbidity and MPV in diabetic patients with acute myocardial infarction.

\section{Materials and methods}

The study conforms to the Declaration of Helsinki. Informed consent for data analysis was obtained from the patients according to the Polish law on patients' rights regarding data registration. Approval for analyzing recorded data was waived by the local bioethics committee on human research given the retrospective nature of the study. Patients with DM admitted with diagnosis of
ST elevation myocardial infarction (STEMI), within $12 \mathrm{~h}$ from symptom onset were enrolled in the study. A total of 277 patients with DM and STEMI undergoing primary percutaneous coronary intervention (PCI) were enrolled. Based on the number of comorbidities the study population was divided into two groups: group $1(N=\mathbf{5 8})$ with $\leq 1$ comorbidity and group $2(N=\mathbf{2 1 9})$ with $\geq 2$ comorbidities. Furthermore, a subanalysis was performed within the multimorbidity group: group $\mathbf{2 A}$ with two or three comorbidities $(N=\mathbf{1 5 6})$ and group $2 \mathrm{~B}$ with at least four comorbidities $(\boldsymbol{N}=\mathbf{6 3})$.

All patients received loading doses of antiplatelet medications (aspirin, clopidogrel) before admission to our hospital (either in the referring hospital or ambulance) according to the guidelines.

Venous blood samples were collected on admission in standardized dipotassium ethylenedinitrotetraacetic acid (EDTA) tubes. The samples were tested within $30 \mathrm{~min}$ of collection to minimize variations due to sample aging. Platelet indices were measured as part of the automated CBC using a Sysmex XS1000i and XE2100 (Sysmex Corporation, Kobe, Japan). The definitions of STEMI and DM have been described in detailed previously [29]. Coronary angiography and percutaneous coronary interventions were performed using standard protocols and guidelines. A culprit lesion was described in the presence of an acute occlusion, intraluminal filling defects (or thrombus), ulcerated plaques, dissection, or intraluminal flaps.

We reviewed the medical records of patients who were admitted with a diagnosis of STEMI and reviewed each of their hospital charts. Comorbidities in the present study were defined as those chronic conditions that were previously diagnosed, and had been documented, in the medical history section of reviewed hospital charts, or that may have been newly diagnosed during the patient's hospital stay. Comorbidities were grouped into two categories: (a) CVD comorbidities which included hypertension (HTN), atrial fibrillation (AF), heart failure (HF), hyperlipidemia, stroke, and peripheral artery disease (PAD), and (b) nonCVD criteria which included chronic obstructive pulmonary disease (COPD), asthma, cancer, anemia, peptic ulcer/GI bleeding, chronic kidney disease (CKD) stage $\geq 3$ (estimated glomerular filtration rate below $60 \mathrm{~mL} / \mathrm{min} / 1.73 \mathrm{~m}^{2}$ ), thyroid disorders (hypo-/hyperthyroidism, goiter), depression, and connective tissue disease (CTD). The afore-mentioned CVD and non-CVD were selected based on the findings of previous reports that have pointed to the association of these conditions with outcomes following AMI [30-33].

We adopted the most widely used definition of multimorbidity - that is, the coexistence of multiple chronic diseases and medical conditions in the same individual (defined as two or more conditions) [34-36]. We used the World Health Organization definition of chronic disease, which is "health 
problems that require ongoing management over a period of years or decades" [37].

\section{Statistical analysis}

Quantitative data are presented as means \pm standard deviations (SD) or medians with interquartile ranges (lower and upper quartiles). Qualitative data are presented as frequencies. The Shapiro-Wilk test was used to determine whether random samples came from a normal distribution. The Chi-square test with Yates' correction was used to compare categorical variables. The unpaired $t$ test was used to compare normally distributed continuous variables between groups. The Mann-Whitney $U$ test was used to compare continuous variables with a distribution other than normal. One-way analysis of variance (ANOVA) and Kruskal-Wallis ANOVA tests were used to compare continuous variables between groups $1,2 \mathrm{~A}$, and $2 \mathrm{~B}$ for variables normally

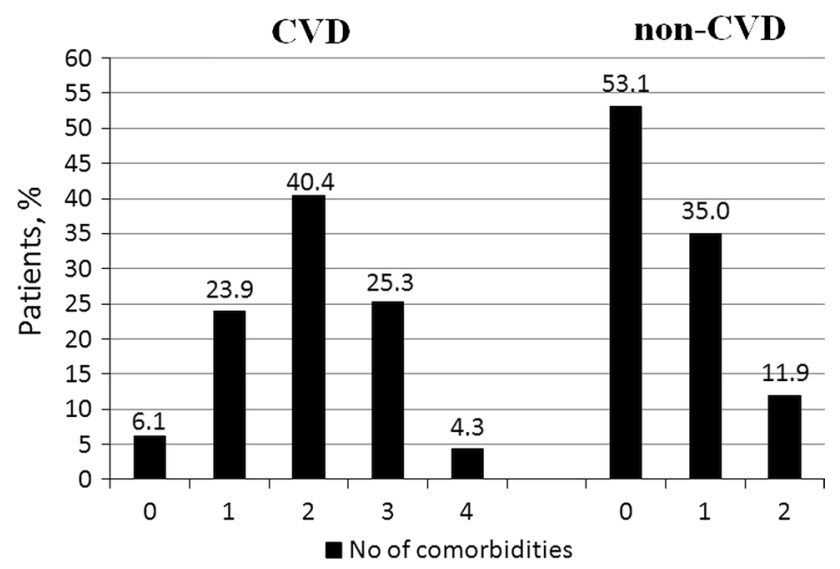

Fig. 1 Distribution of the number of comorbid cardiovascular (CVD) and non-cardiovascular (non-CVD) conditions

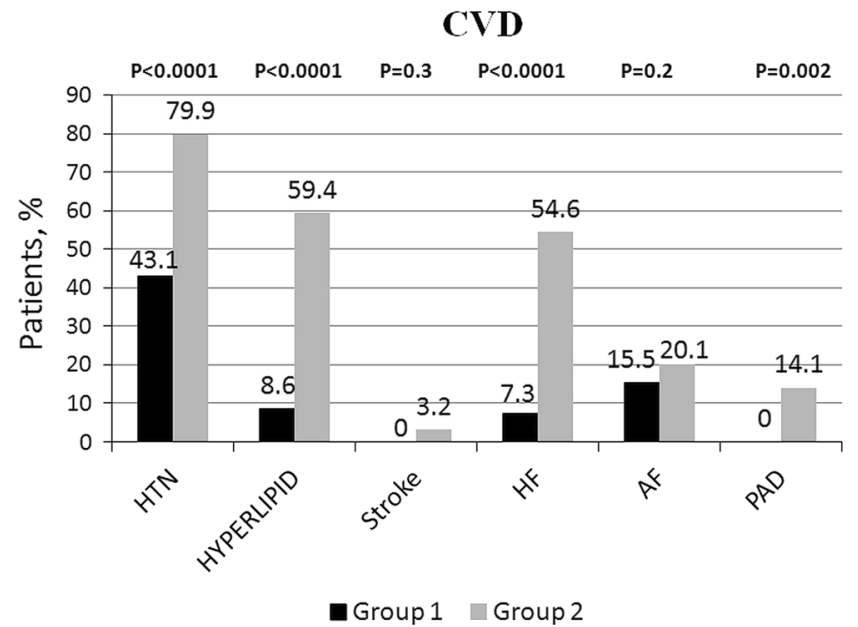

and not normally distributed, respectively. The relationship between MPV and clinical/laboratory variables was evaluated by Spearman's rank correlation coefficient. A value of two tailed $P<0.05$ was considered significant.

\section{Results}

The median number of comorbidities was three. In the study population, $15.9 \%$ of patients had one comorbidity and $22.0,34.3$, and $22.7 \%$ of patients had two, three or at least four comorbid conditions, respectively. The number of comorbid cardiovascular (CVD) and non-cardiovascular (non-CVD) conditions is depicted in Fig. 1. The two study groups differed with respect to the use of insulin and metformin. Patients with multimorbidity had more impaired left ventricular systolic function and required longer in-hospital stay ( 7.5 vs 9 days $P=0.04$ ) (Table 1 ). Figure 2 depicts the prevalence of selected CVD and non-CVD comorbidities among patients with STEMI and DM. Angiographic characteristics were similar in all study groups (Table 2). Multimorbid patients had elevated levels of total cholesterol and LDL cholesterol (Table 3).

If we now turn to platelet volume indices, both MPV and PDW were elevated in multimorbid patients (9.3 vs $10.8 \mathrm{fl}$ and 9.5 vs $10.3 \mathrm{fl}$, respectively). Similarly, MPVto-platelet count (MPV/PC) ratio was increased in patients with multimorbidity (Table 4). What is more, the highest platelet volume indices were observed in patients with at least four comorbid conditions (Table 4). Figure 3 demonstrates median MPV values across all studied CVD and non-CVD comorbid conditions. Table 5 provides the correlations between the studied platelet volume indices and the number of comorbid conditions. There was a moderate positive correlation between MPV and the total number of

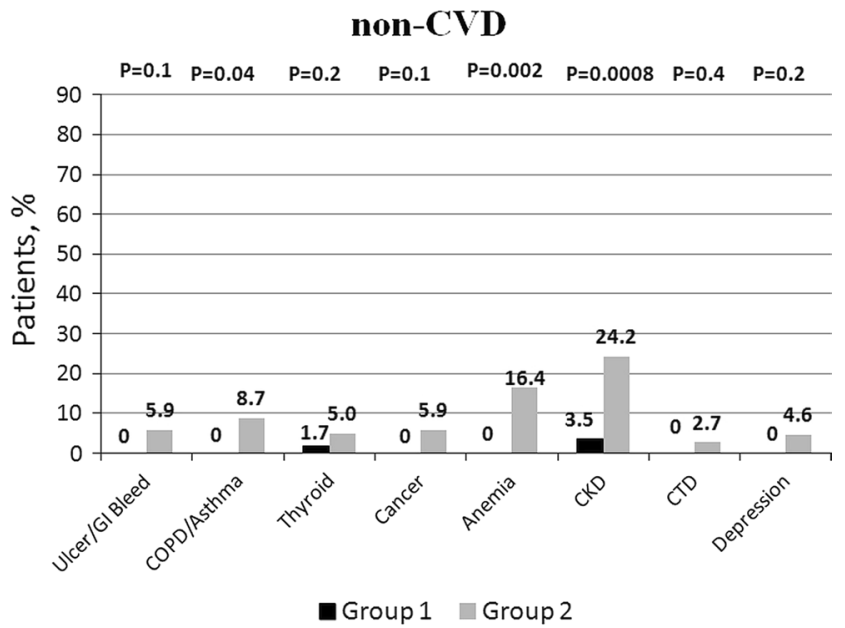

Fig. 2 Prevalence of selected cardiovascular (CVD) and non-cardiovascular (non-CVD) comorbidities 
Table 1 Patients' baseline and clinical characteristics

\begin{tabular}{|c|c|c|c|c|c|c|c|}
\hline & Group $1 N=58$ & Group $2 N=219$ & $P$ & Group $1 N=58$ & Group $2 \mathrm{~A} N=156$ & Group 2B $N=63$ & $P$ \\
\hline Age, years $($ mean $\pm S D)$ & $63 \pm 8$ & $64 \pm 10$ & 0.5 & $63 \pm 8$ & $63 \pm 10$ & $65 \pm 10$ & 0.6 \\
\hline Men, $N(\%)$ & $37(63.8 \%)$ & $126(57.5 \%)$ & 0.4 & $37(63.8 \%)$ & $98(62.8 \%)$ & $28(44.4 \%)$ & 0.03 \\
\hline $\begin{array}{l}\text { Prior myocardial infarction, } \\
\quad N(\%)\end{array}$ & $11(19.0 \%)$ & $64(29.3 \%)$ & 0.1 & $11(19.0 \%)$ & $42(27.1 \%)$ & $22(34.9 \%)$ & 0.1 \\
\hline Smoking, $N(\%)$ & $12(20.7 \%)$ & $26(11.9 \%)$ & 0.04 & $12(20.7 \%)$ & $20(12.8 \%)$ & $6(9.5 \%)$ & 0.04 \\
\hline $\begin{array}{l}\text { Time from symptom onset, } \\
\text { hours [median (interquartile } \\
\text { range)] }\end{array}$ & $5.0(3.0-6.0)$ & $4.0(3.0-7.0)$ & 0.8 & $5.0(3.0-6.0)$ & $4.0(3.0-7.0)$ & $4.0(3.0-8.0)$ & 0.6 \\
\hline Cardiogenic shock, $N(\%)$ & $8(13.8 \%)$ & $34(15.5 \%)$ & 0.7 & $8(13.8 \%)$ & $25(16.0 \%)$ & $9(14.3 \%)$ & 0.9 \\
\hline Insulin $^{\mathrm{a}}, N(\%)$ & $24(41.4 \%)$ & $138(63.8 \%)$ & 0.002 & $24(41.4 \%)$ & $91(58.3 \%)$ & $47(74.6 \%)$ & $<0.001$ \\
\hline Metformin $^{\mathrm{a}}, N(\%)$ & $34(58.6 \%)$ & $88(40.2 \%)$ & 0.02 & $34(58.6 \%)$ & $65(41.7 \%)$ & $23(36.5 \%)$ & 0.04 \\
\hline Sulfonylureas ${ }^{\mathrm{a}}, N(\%)$ & $19(32.8 \%)$ & $70(32.0 \%)$ & 0.8 & $19(32.8 \%)$ & $47(30.1 \%)$ & $23(36.5 \%)$ & 0.5 \\
\hline HbA1c, $(\%)$ & $7.7(6.9-8.5)$ & $7.5(6.9-8.0)$ & 0.3 & $7.7(6.9-8.5)$ & $7.6(7.0-8.3)$ & $7.5(6.8-8.4)$ & 0.3 \\
\hline $\begin{array}{l}\text { LVEF, (\%) [median (inter- } \\
\text { quartile range)] }\end{array}$ & $47(45-51)$ & $40(35-45)$ & $<0.001$ & $47(45-51)$ & $42(35-45)$ & $39(32-42)$ & $<0.001$ \\
\hline $\begin{array}{l}\text { Hospital stay, days [median } \\
\text { (interquartile range)] }\end{array}$ & $7.5(6-10)$ & $9(6-12)$ & 0.04 & $7.5(6-10)$ & $9(6-12)$ & $10(6-13)$ & 0.055 \\
\hline
\end{tabular}

$S D$ standard deviation; $L V E F$ left ventricular ejection fraction

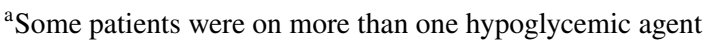

Table 2 Angiographic findings

\begin{tabular}{|c|c|c|c|c|c|c|c|}
\hline & Group $1 N=58$ & Group $2 N=219$ & $P$ & Group $1 N=58$ & Group 2A $N=156$ & Group $2 \mathrm{~b} N=63$ & $P$ \\
\hline $\begin{array}{l}\text { Multivessel } \\
\text { CAD, N (\%) }\end{array}$ & $28(48.3 \%)$ & $111(50.7 \%)$ & 0.8 & $28(48.3 \%)$ & $77(49.4 \%)$ & $34(54.0 \%)$ & 0.2 \\
\hline \multicolumn{8}{|c|}{ Initial TIMI flow, $N(\%)$} \\
\hline 0 & $35(60.3 \%)$ & $147(67.5 \%)$ & \multirow{4}{*}{0.6} & $35(60.3 \%)$ & $103(66.0 \%)$ & $44(71.0 \%)$ & \\
\hline 1 & $12(20.7 \%)$ & $36(16.5 \%)$ & & $12(20.7 \%)$ & $30(19.2 \%)$ & $7(9.7 \%)$ & \multirow[t]{3}{*}{0.4} \\
\hline 2 & $11(19.0 \%)$ & $36(16.5 \%)$ & & $11(19.0 \%)$ & $23(14.8 \%)$ & $12(19.3 \%)$ & \\
\hline 3 & $0(0 \%)$ & $0(0 \%)$ & & $0(0 \%)$ & $0(0 \%)$ & $0(0 \%)$ & \\
\hline \multicolumn{8}{|c|}{ Final TIMI flow, $N(\%)$} \\
\hline 0 & $2(3.4 \%)$ & $13(5.9 \%)$ & \multirow{4}{*}{0.4} & $2(3.4 \%)$ & $6(3.8 \%)$ & $4(6.3 \%)$ & \\
\hline 1 & $1(1.7 \%)$ & $2(0.9 \%)$ & & $1(1.7 \%)$ & $2(1.3 \%)$ & $0(0 \%)$ & \multirow[t]{3}{*}{0.2} \\
\hline 2 & $3(5.2 \%)$ & $20(9.1 \%)$ & & $3(5.2 \%)$ & $16(10.2 \%)$ & $3(4.8 \%)$ & \\
\hline 3 & $52(89.9 \%)$ & $184(84.0 \%)$ & & $52(89.9 \%)$ & $132(84.6 \%)$ & $56(88.9 \%)$ & \\
\hline
\end{tabular}

$C A D$ coronary artery disease, $T I M I$ thrombolysis in myocardial infarction

comorbidities, the number of CVD comorbidities, and the number of non-CVD comorbidities. Unlike MPV, PDW correlated only with the number of CVD comorbidities.

\section{Discussion}

We investigated the effect of multimorbidity on MPV in diabetic patients with acute myocardial infarction. There are several key findings of our study. First and foremost, multimorbid patients had increased platelet volume indices, including MPV. Second, MPV values increased with the increasing number of comorbid conditions with the highest platelet volume indices were observed in patients with at least four comorbid conditions. And finally, MPV values were elevated in some, but not all CVD and nonCVD conditions. More importantly, it appeared that rather disease clusters than the specific disease type were associated with increased platelet volume indices.

We found that multimorbidity was highly prevalent among diabetic patients with STEMI. This finding is consistent with previous reports [2, 3]. Specific conditions have been previously linked to elevated MPV; however, 
Table 3 Laboratory findings

\begin{tabular}{|c|c|c|c|c|c|c|c|}
\hline & Group $1 N=58$ & Group $2 N=219$ & $P$ & Group $1 N=58$ & Group 2A $N=156$ & Group $2 \mathrm{~b} N=63$ & $P$ \\
\hline Leukocytes $\left(10^{3} / \mathrm{mm}^{3}\right)$ & $14.5 \pm 4.8$ & $13.9 \pm 5.6$ & 0.6 & $14.5 \pm 4.8$ & $14.2 \pm 6.0$ & $13.2 \pm 5.0$ & 0.6 \\
\hline Erythrocytes $\left(10^{6} / \mathrm{mm}^{3}\right)$ & $4.5 \pm 0.5$ & $4.5 \pm 0.6$ & 0.9 & $4.5 \pm 0.5$ & $4.5 \pm 0.6$ & $4.5 \pm 0.8$ & 0.9 \\
\hline Hemoglobin (g/dL) & $14.5 \pm 1.3$ & $13.9 \pm 1.6$ & 0.4 & $14.5 \pm 1.3$ & $14.2 \pm 3.0$ & $13.4 \pm 2.4$ & 0.4 \\
\hline Hematocrit (\%) & $42 \pm 5$ & $41 \pm 5$ & 0.5 & $42 \pm 5$ & $41 \pm 5$ & $40 \pm 5$ & 0.5 \\
\hline Platelet count $\left(10^{3} / \mathrm{mm}^{3}\right)$ & $228 \pm 66$ & $217 \pm 70$ & 0.7 & $228 \pm 66$ & $219 \pm 63$ & $212 \pm 82$ & 0.9 \\
\hline Admission glycemia (mmol/l) & $9.7 \pm 2.7$ & $9.3 \pm 3.8$ & 0.7 & $9.7 \pm 2.7$ & $9.4 \pm 3.9$ & $9.1 \pm 3.8$ & 0.4 \\
\hline Total cholesterol (mmol/l) & $4.7(4.4-5.8)$ & $5.7(4.9-7.1)$ & 0.01 & $4.7(4.4-5.8)$ & $6.0(4.8-7.3)$ & $5.6(5.0-6.6)$ & 0.02 \\
\hline HDL cholesterol (mmol/l) & $1.4(1.1-1.7)$ & $1.3(1.1-1.6)$ & 0.8 & $1.4(1.1-1.7)$ & $1.4(1.0-1.7)$ & $1.2(1.1-1.6)$ & 0.6 \\
\hline LDL cholesterol (mmol/l) & $3.0(2.5-3.9)$ & $4.2(3.2-4.6)$ & 0.01 & $3.0(2.5-3.9)$ & $4.6(3.6-5.0)$ & $3.9(3.2-4.6)$ & 0.02 \\
\hline Triglycerides (mmol/l) & $1.1(0.8-1.7)$ & $1.2(0.9-1.8)$ & 0.7 & $1.1(0.8-1.7)$ & $1.1(0.8-1.7)$ & $1.3(0.9-1.9)$ & 0.5 \\
\hline Serum creatinine $(\mu \mathrm{mol} / \mathrm{l})$ & $83(76-101)$ & $89(77-114)$ & 0.5 & $83(76-101)$ & $86(77-99)$ & $84(76-108)$ & 0.3 \\
\hline eGFR $\left(\mathrm{ml} / \mathrm{min}\right.$ per $\left.1.73 \mathrm{~m}^{2}\right)$ & $75(67-87)$ & $70(60-85)$ & 0.4 & $75(67-87)$ & $72(62-87)$ & $69(50-80)$ & 0.9 \\
\hline
\end{tabular}

Table 4 Platelet volume indices

\begin{tabular}{lccccccc}
\hline & Group $1 N=58$ & Group $2 N=219$ & $P$ & Group $1 N=58$ & Group 2A $N=156$ & Group 2b $N=63$ & $P$ \\
\hline MPV (fl) & $9.3(8.1-11.0)$ & $10.8(8.9-12.3)$ & 0.03 & $9.3(8.1-11.0)$ & $10.5(8.7-12.0)$ & $11.1(9.1-12.5)$ & 0.02 \\
PDW (fl) & $9.5(8.5-10.4)$ & $10.3(8.9-11.1)$ & 0.03 & $9.5(8.5-10.4)$ & $10.1(8.8-10.9)$ & $10.6(9.1-11.4)$ & 0.04 \\
MPV/PC (fl/10 $)$ & $0.408(0.388-0.435)$ & $0.497(0.412-0.513)$ & 0.02 & $0.408(0.388-0.435)$ & $0.453(0.399-0.501)$ & $0.517(0.432-0.541)$ & 0.03 \\
\hline
\end{tabular}

$M P V$ mean platelet volume, $M P V / P C$ mean platelet volume to platelet count ratio, $P D W$ platelet distribution width
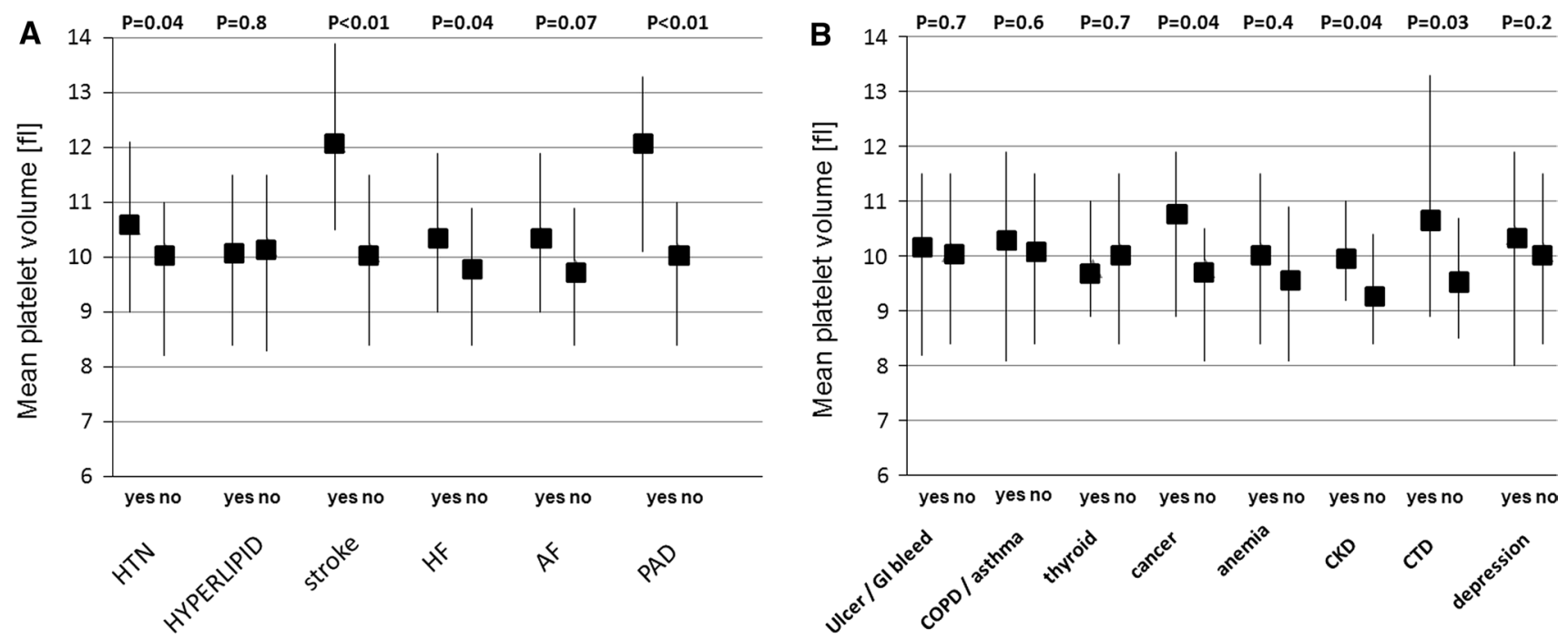

Fig. 3 Median (interquartile range) values of mean platelet volume across the spectrum of cardiovascular disease (CVD) and non-CVD conditions

we did not find any prior studies assessing the effect of multimorbidity on MPV.

Based on recent studies, inflammation-a biological mechanism-appears to be a common mechanism in numerous chronic illness, especially multimorbidity. Friedman et al. [38] studied 1229 patients from the Survey of Mid-Life in the United States (MIDUS). They assessed direct relationships between multimorbidity and activities of daily living as well as indirect associations with a latent variable for inflammation (indicated by circulating levels of interleukin 6, C-reactive protein, and fibrinogen) as a mediator. The authors reported that after adjustment for potential confounds, multimorbidity was positively associated with inflammation $(P<0.001)$ and functional 
Table 5 Correlation between platelet volume indices and the number of comorbidities

\begin{tabular}{|c|c|c|c|c|c|c|}
\hline & \multicolumn{2}{|l|}{ MPV } & \multicolumn{2}{|c|}{ PDW } & \multicolumn{2}{|c|}{$\mathrm{MPV} / \mathrm{PC}$} \\
\hline & $R$ & $P$ & $R$ & $P$ & $R$ & $P$ \\
\hline Total number of comorbidities & 0.45 & 0.03 & 0.14 & 0.2 & 0.18 & 0.04 \\
\hline Number of cardiovascular comorbidities & 0.48 & 0.02 & 0.23 & 0.03 & 0.20 & 0.04 \\
\hline Number of non-cardiovascular comorbidities & 0.52 & 0.04 & 0.15 & 0.3 & 0.10 & 0.4 \\
\hline
\end{tabular}

$M P V$ mean platelet volume, $M P V / P C$ mean platelet volume to platelet count ratio, $P D W$ platelet distribution width limitations $(P<0.001)$, and inflammation partially mediated the link between multimorbidity and functional limitations $(P<0.01)$ [38]. Moreover, a wide range of populationbased studies have shown that inflammatory state is higher in adults with single chronic medical disease [39-41] and seems to progress further with every additional chronic illness in adults with multimorbidity [42, 43]. Fabri et al. [42] studied 1018 participants of the InCHIANTI Study and reported that higher baseline IL-6 concentrations and steeper increase of IL-6 concentrations were significantly and independently associated with a abrupt increase in multimorbidity over time $(P<0.001$ and $P=0.003$, respectively).

In reviewing the literature, no data was found on the association between multimorbidity and increased MPV. However, given the impact of multimorbidity on inflammation, the effect of multimorbidity on MPV can be explained in part by the proximity of thrombosis and inflammation. Although for many years platelets were recognized as a key element in thrombosis and hemostasis, more recently it has become more evident that platelet activation is also a hallmark feature in inflammation. Thus, it seems that platelets exhibit the ability to influence a wide range of seemingly unrelated pathophysiologic events [44-46]. In fact, it has been demonstrated that thrombosis and inflammation share several key molecular mechanisms and in fact are 2 intrinsically linked processes [46]. Platelet volume is determined both during megakaryopoiesis and during thrombopoiesis. Megakaryocytic maturation, platelet production, and platelet size could be regulated by cytokines, such as IL-6, granulocytes colony-stimulating factor (G-CSF), and macrophage colony-stimulating factor (M-CSF) [47]. Brown et al. [48] have demonstrated that patients with vascular disease, particularly diabetics, have an altered megakaryocyte (MK) ploidy distribution, showing a shift toward higher ploidy in association with an increased platelet mass (count $\times$ volume). Changes in platelets in diabetes probably reflected MK changes, which themselves are a response to systemic change.

Elevated MPV along with increased inflammation biomarkers (e.g., C-reactive [CRP], interleukin-6 [IL-6] among other) were reported in many conditions which are characterized by low-grade inflammation including ischemic stroke [49], utricaria [50], postoperative atrial fibrillation
[51], adverse outcomes following percutaneous coronary intervention [52], myocardial infarction [53], urinary tract infection [54], exacerbations of COPD [55], hypertension [56], rheumatoid arthritis (RA) [57], osteoarthritis [58], and pneumonia [59].

In contrast, MPV was frequently found to be decreased in the presence of active high-grade inflammation; that is, active phase of RA, ankylosing spondylitis [60], ulcerative colitis, Crohn's disease [61], and systemic lupus erythematosus (SLE) [62].

Finally, these results help to highlight the conceptual relationship between multimorbidity and platelet volume indices and corresponding worse outcomes. In many instances, the severity of MPV increase is not just linked to the type of comorbid conditions, but also should be interpreted in the context of the number of comorbid illnesses.

\section{Conclusions}

These findings indicate that multimorbidity is associated with an increase in platelet volume indices. Multimorbidity was associated with increased platelet volume indices. MPV values increased with the increasing number of comorbid conditions with the highest platelet volume indices were observed in patients with at least four comorbid conditions. And finally, MPV values were elevated in some, but not all CVD and non-CVD conditions. More importantly, it appeared that rather disease clusters than the specific disease type were associated with increased platelet volume indices. It would seem that comorbid conditions exert synergistic rather than additive effect on MPV. This research provides a framework for the exploration of the effect of disease clusters on the outcomes rather than focusing on the specific entities.

\section{Study limitations}

The study was carried out among patients with DM. As it frequently is a major component of multimorbidity, our results should be interpreted with caution in terms of general population. The selection of the chronic conditions for the purpose of diagnosing multimorbidity in the current 
study was made based on findings from previous studies that have examined the associations of these comorbidities with the prognosis of patients hospitalized with acute myocardial infarction. In addition, these data are cross-sectional, meaning that causal associations are not clear. All chronic conditions included in our study had equal weight in the principal component analysis, since we did not have any data regarding the severity or duration of a chronic disease. The small number of patients without multimorbidity could have contributed to the underdetection of meaningful differences in some of the patients' characteristics, especially in platelet volume indices among patients with non-CVD comorbidities. We have used EDTA for anticoagulation of whole blood prior to automated cell counting. Some reports show that MPV values may increase with the use of EDTA due to platelet swelling, thus, suggesting the use of acid citrate as anticoagulant. However, most studies indicate that MPV can be measured accurately by both methods of anticoagulation-EDTA and citrate-if analysis be performed within $1 \mathrm{~h}$ of sampling. We did not routinely register microvascular complications (e.g., diabetic neuropathy, retinopathy, and nephropathy) which have been also reported to be associated with increased MPV [24]. In addition, we have not registered information on several patient-associated features (e.g., socioeconomic status or psychological factors) which may have influenced some of the observed associations. Despite these limitations, this is an all-comers study among a highrisk population of patients with DM and STEMI.

\section{Compliance with ethical standards}

Conflict of interest The authors declare that they have no conflict of interest.

Statement of Human and Animal Rights All procedures followed were in accordance with the ethical standards of the responsible committee on human experimentation (institutional and national) and with the 1975 Declaration of Helsinki, as revised in 2008.

Informed consent Informed consent was obtained from all patients for being included in the study.

Open Access This article is distributed under the terms of the Creative Commons Attribution 4.0 International License (http://creativecommons.org/licenses/by/4.0/), which permits unrestricted use, distribution, and reproduction in any medium, provided you give appropriate credit to the original author(s) and the source, provide a link to the Creative Commons license, and indicate if changes were made.

\section{References}

1. Kharroubi AT, Darwish HM (2015) Diabetes mellitus: the epidemic of the century. World J Diabetes 6:850-867
2. Druss BG, Marcus SC, Olfson M, Tanielian T, Elinson L, Pincus HA (2001) Comparing the national economic burden of five chronic conditions. Health Aff (Millwood) 20:233-241

3. Wolff JL, Starfield B, Anderson G (2002) Prevalence, expenditures, and complications of multiple chronic conditions in the elderly. Arch Intern Med 162:2269-2276

4. Diederichs C, Berger K, Bartels DB (2011) The measurement of multiple chronic diseases-a systematic review on existing multimorbidity indices. J Gerontol A Biol Sci Med Sci 66:301-311

5. Teljeur C, Smith SM, Paul G, Kelly A, O’Dowd T (2013) Multimorbidity in a cohort of patients with type 2 diabetes. Eur J Gen Pract 19:17-22

6. Valent F, Tonutti L, Grimaldi F (2017) Does diabetes mellitus comorbidity affect in-hospital mortality and length of stay? Analysis of administrative data in an Italian Academic Hospital. Acta Diabetol. https://doi.org/10.1007/s00592-017-1050-6 [Epub ahead of print]

7. Marzona I, Avanzini F, Lucisano G et al (2017) Are all people with diabetes and cardiovascular risk factors or microvascular complications at very high risk? Findings from the Risk and Prevention Study. Acta Diabetol 54:123-131

8. Hudzik B, Szkodzinski J, Hawranek M, Lekston A, Polonski L, Gasior M (2016) CHA2DS2-VASc score is useful in predicting poor 12-month outcomes following myocardial infarction in diabetic patients without atrial fibrillation. Acta Diabetol 53:807-815

9. Lynch CP, Gebregziabher M, Axon RN, Hunt KE, Payne E, Egede LE (2015) Geographic and racial/ethnic variations in patterns of multimorbidity burden in patients with type 2 diabetes. J Gen Intern Med 30:25-32

10. Alonso-Moran E, Orueta JF, Fraile Esteban JI et al (2014) The prevalence of diabetes-related complications and multimorbidity in the population with type 2 diabetes mellitus in the Basque Country. BMC Public Health 14:1059

11. Lin PJ, Kent DM, Winn A, Cohen JT, Neumann PJ (2015) Multiple chronic conditions in type 2 diabetes mellitus: prevalence and consequences. Am J Manag Care 21:e23-e34

12. Valettas N, Herrmann HC (2003) The role of platelets and platelet inhibition in acute myocardial infarction. Coron Artery Dis 14:357-363

13. Ferreiro JL, Angiolillo DJ (2011) Diabetes and antiplatelet therapy in acute coronary syndrome. Circulation 123:798-813

14. Michelson AD (2009) Methods for the measurement of platelet function. Am J Cardiol 103:20A-26A

15. Leader A, Pereg D, Lishner M (2012) Are platelet volume indices of clinical use? A multidisciplinary review. Ann Med 44:805-816

16. Hekimsoy Z, Payzin B, Ornek T, Kandogan G (2004) Mean platelet volume in Type 2 diabetic patients. J Diabetes Complicat $18: 173-176$

17. Coban E, Bostan F, Ozdogan M (2006) The mean platelet volume in subjects with impaired fasting glucose. Platelets 17:67-69

18. Coban E, Afacan B (2008) The effect of rosuvastatin treatment on the mean platelet volume in patients with uncontrolled primary dyslipidemia with hypolipidemic diet treatment. Platelets 19:111-114

19. Demirtunc R, Duman D, Basar M, Bilgi M, Teomete M, Garip $\mathrm{T}$ (2009) The relationship between glycemic control and platelet activity in type 2 diabetes mellitus. J Diabetes Complicat 23:89-94

20. Huczek Z, Kochman J, Filipiak KJ et al (2005) Mean platelet volume on admission predicts impaired reperfusion and long-term mortality in acute myocardial infarction treated with primary percutaneous coronary intervention. J Am Coll Cardiol 46:284-290

21. Lekston A, Hudzik B, Hawranek M et al (2014) Prognostic significance of mean platelet volume in diabetic patients with STelevation myocardial infarction. J Diabetes Complicat 28:652-657 
22. Tasci I, Basgoz BB, Saglam K (2016) Glycemic control and the risk of microvascular complications in people with diabetes mellitus. Acta Diabetol 53:129-130

23. Anjana RM, Amutha A, Mohan V (2016) Regularity of followup, glycemic burden, and risk of microvascular complications in patients with type 2 diabetes: a 9-year follow-up study. Acta Diabetol 53:131-132

24. Papanas N, Symeonidis G, Maltezos E et al (2004) Mean platelet volume in patients with type 2 diabetes mellitus. Platelets 15:475-478

25. Pyo JS, Sohn JH, Kang G (2016) Diagnostic and prognostic roles of the mean platelet volume in malignant tumors: a systematic review and meta-analysis. Platelets 27:722-728

26. Steiropoulos P, Papanas N, Nena E, Xanthoudaki M, Goula T, Froudarakis M, Pita E, Maltezos E, Bouros D (2013) Mean platelet volume and platelet distribution width in patients with chronic obstructive pulmonary disease: the role of comorbidities. Angiology 64:535-539

27. Ju HY, Kim JK, Hur SM et al (2015) Could mean platelet volume be a promising biomarker of progression of chronic kidney disease? Platelets 26:143-147

28. Gasparyan AY, Ayvazyan L, Mikhailidis DP, Kitas GD (2011) Mean platelet volume: a link between thrombosis and inflammation? Curr Pharm Des 17:47-58

29. Hudzik B, Szkodzinski J, Gorol J et al (2015) Platelet-to-lymphocyte ratio is a marker of poor prognosis in patients with diabetes mellitus and ST-elevation myocardial infarction. Biomark Med 9:199-207

30. Nguyen HL, Nguyen QN, Ha DA, Phan DT, Nguyen NH, Goldberg RJ (2014) Prevalence of comorbidities and their impact on hospital management and short-term outcomes in Vietnamese patients hospitalized with a first acute myocardial infarction. PLoS ONE 9:e108998

31. McManus DD, Nguyen HL, Saczynski JS, Tisminetzky M, Bourell P, Goldberg RJ (2012) Multiple cardiovascular comorbidities and acute myocardial infarction: temporal trends (1990-2007) and impact on death rates at 30 days and 1 year. Clin Epidemiol $4: 115-123$

32. Schmidt M, Jacobsen JB, Lash TL, Botker HE, Sorensen HT (2012) 25 year trends in first time hospitalisation for acute myocardial infarction, subsequent short and long term mortality, and the prognostic impact of sex and comorbidity: a Danish nationwide cohort study. BMJ 344:e356

33. Chen HY, Saczynski JS, McManus DD et al (2013) The impact of cardiac and noncardiac comorbidities on the short-term outcomes of patients hospitalized with acute myocardial infarction: a population-based perspective. Clin Epidemiol 5:439-448

34. Smith SM, Soubhi H, Fortin M, Hudon C, O'Dowd T (2012) Managing patients with multimorbidity: systematic review of interventions in primary care and community settings. BMJ 345:e5205

35. Fortin M, Soubhi H, Hudon C, Bayliss EA, van den Akker M (2007) Multimorbidity's many challenges. BMJ 334:1016-1017

36. van den Akker M, Buntinx F, Metsemakers JF, Roos S, Knottnerus JA (1998) Multimorbidity in general practice: prevalence, incidence, and determinants of co-occurring chronic and recurrent diseases. J Clin Epidemiol 51:367-375

37. World Health Organization. Innovative care for chronic conditions: building blocks for action. Global report. World Health Organization.

38. Friedman EM, Christ SL, Mroczek DK (2015) inflammation partially mediates the association of multimorbidity and functional limitations in a national sample of middle-aged and older adults: the MIDUS study. J Aging Health 27:843-863

39. Bautista LE, Vera LM, Arenas IA, Gamarra G (2005) Independent association between inflammatory markers (C-reactive protein, interleukin-6, and TNF-alpha) and essential hypertension. J Hum Hypertens 19:149-154

40. Blake GJ, Ridker PM (2003) C-reactive protein and other inflammatory risk markers in acute coronary syndromes. J Am Coll Cardiol 41:37S-42S

41. Hu FB, Meigs JB, Li TY, Rifai N, Manson JE (2004) Inflammatory markers and risk of developing type 2 diabetes in women. Diabetes 53:693-700

42. Fabbri E, An Y, Zoli M et al (2015) Aging and the burden of multimorbidity: associations with inflammatory and anabolic hormonal biomarkers. J Gerontol A Biol Sci Med Sci 70:63-70

43. Friedman EM, Ryff CD (2012) Living well with medical comorbidities: a biopsychosocial perspective. J Gerontol B Psychol Sci Soc Sci 67:535-544

44. Franco AT, Corken A, Ware J (2015) Platelets at the interface of thrombosis, inflammation, and cancer. Blood 126:582-588

45. Phipps RP (2011) Platelets at the interface between thrombosis, inflammation and immunity. Thromb Res 127:179

46. Wagner DD, Burger PC (2003) Platelets in inflammation and thrombosis. Arterioscler Thromb Vasc Biol 23:2131-2137

47. Kaushansky K (1998) Growth factors and hematopoietic cell fate. A new feature: controversies in hematology. Blood 92:344-345

48. Brown AS, Hong Y, de Belder A et al (1997) Megakaryocyte ploidy and platelet changes in human diabetes and atherosclerosis. Arterioscler Thromb Vasc Biol 17:802-807

49. Arikanoglu A, Yucel Y, Acar A, Cevik MU, Akil E, Varol S (2013) The relationship of the mean platelet volume and C-reactive protein levels with mortality in ischemic stroke patients. Eur Rev Med Pharmacol Sci 17:1774-1777

50. Magen E, Mishal J, Zeldin Y et al (2010) Increased mean platelet volume and $\mathrm{C}$-reactive protein levels in patients with chronic urticaria with a positive autologous serum skin test. Am J Med Sci 339:504-508

51. Erdem K, Ayhan S, Ozturk S et al (2014) Usefulness of the mean platelet volume for predicting new-onset atrial fibrillation after isolated coronary artery bypass grafting. Platelets 25:23-26

52. Moon AR, Choi DH, Jahng SY et al (2016) High-sensitivity C-reactive protein and mean platelet volume as predictive values after percutaneous coronary intervention for long-term clinical outcomes: a comparable and additive study. Blood Coagul Fibrinolysis 27:70-76

53. Kim D, Choi DH, Kim BB, Choi SW, Park KH, Song H (2016) Prediction of Infarct Transmurality From C-Reactive Protein Level and Mean Platelet Volume in Patients With ST-Elevation Myocardial Infarction: comparison of the Predictive Values of Cardiac Enzymes. J Clin Lab Anal 30:930-940

54. Lee IR, Shin JI, Park SJ, Oh JY, Kim JH (2015) Mean platelet volume in young children with urinary tract infection. Sci Rep 5:18072

55. Agapakis DI, Massa EV, Hantzis I et al (2016) The role of mean platelet volume in chronic obstructive pulmonary disease exacerbation. Respir Care 61:44-49

56. Wasilewska A, Tenderenda E, Taranta-Janusz K, Zoch-Zwierz W (2010) High-sensitivity C-reactive protein and mean platelet volume in paediatric hypertension. Pediatr Nephrol 25:1519-1527

57. Yazici S, Yazici M, Erer B, Calik Y, Ozhan H, Ataoglu S (2010) The platelet indices in patients with rheumatoid arthritis: mean platelet volume reflects disease activity. Platelets 21:122-125

58. Tasoglu O, Sahin A, Karatas G, Koyuncu E, Tasoglu I, Tecimel O, Ozgirgin N (2017) Blood mean platelet volume and platelet lymphocyte ratio as new predictors of hip osteoarthritis severity. Medicine (Baltimore) 96:e6073

59. Lee JH, Yoon SY, Kim HS, Lim CS (2015) Characteristics of the mean platelet volume, neutrophil to lymphocyte ratio, and $\mathrm{C}$-reactive protein compared to the procalcitonin level in pneumonia patients. Platelets 26:278-280 
60. Kisacik B, Tufan A, Kalyoncu U et al (2008) Mean platelet volume (MPV) as an inflammatory marker in ankylosing spondylitis and rheumatoid arthritis. Joint Bone Spine 75:291-294

61. Kapsoritakis AN, Koukourakis MI, Sfiridaki A et al (2001) Mean platelet volume: a useful marker of inflammatory bowel disease activity. Am J Gastroenterol 96:776-781
62. Delgado-Garcia G, Galarza-Delgado DA, Colunga-Pedraza I et al (2016) Mean platelet volume is decreased in adults with active lupus disease. Rev Bras Reumatol Engl Ed. 56:504-508 